\title{
Article \\ Numerical Analysis and Experimental Verification of Resistance Additive Manufacturing
}

\author{
Suli $\mathrm{Li}^{1,2}$, Kaiyue $\mathrm{Ma}^{1,2}$, Chao $\mathrm{Xu}^{1, *}$, Laixia Yang ${ }^{1,2}$ and Bingheng $\mathrm{Lu}^{2}$ \\ 1 School of Mechanical Engineering, Xi'an University of Science and Technology, Xi'an 710054, China;

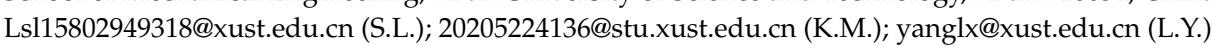 \\ 2 State Key Laboratory for Manufacturing Systems Engineering, Xi'an Jiaotong University, Xi'an 710049, China; \\ bhenglu@163.com \\ * Correspondence: Chaoxu@xust.edu.cn
}

Citation: Li, S.; Ma, K.; Xu, C.; Yang, L.; Lu, B. Numerical Analysis and Experimental Verification of Resistance Additive Manufacturing. Crystals 2022, 12, 193. https:// doi.org/10.3390/cryst12020193

Academic Editors: Hao Yi, Huajun Cao, Menglin Liu, Le Jia and Pavel Lukáč

Received: 30 December 2021

Accepted: 25 January 2022

Published: 28 January 2022

Publisher's Note: MDPI stays neutral with regard to jurisdictional claims in published maps and institutional affiliations.

Copyright: (C) 2022 by the authors. Licensee MDPI, Basel, Switzerland. This article is an open access article distributed under the terms and conditions of the Creative Commons Attribution (CC BY) license (https:// creativecommons.org/licenses/by/ $4.0 /)$

\begin{abstract}
In recent years, scholars have proposed a metal wire forming method based on the Joule heat principle in order to improve the accuracy of additive manufacturing and reduce energy consumption and cost, but it is still in the theoretical stage. In this paper, a mathematical model of resistance additive manufacturing was established using finite element software, and the temperature variation of the melting process under different currents was analyzed. A suitable current range was preliminarily selected, and an experimental system was built. Through experimental study of the current and wire feeding speed, the influences of different process parameters on the forming appearance of the coating were analyzed. The results showed that the forming appearance was the best for Ti-6Al-4V titanium alloy wire with a diameter of $0.8 \mathrm{~mm}$, when the current was $160 \mathrm{~A}$, the voltage was $10 \mathrm{~V}$, the wire feeding speed was $2.4 \mathrm{~m} / \mathrm{min}$, the workbench moving speed was $5 \mathrm{~mm} / \mathrm{s}$, and the gas flow rate was $0.7 \mathrm{~m}^{3} / \mathrm{h}$. Finally, the process parameters were used for continuous single-channel multilayer printing, verified the feasibility of the process at the experimental level and provided reference data for the subsequent development of this technology.
\end{abstract}

Keywords: additive manufacturing; joule thermal; mathematical model; process parameters

\section{Introduction}

With the demand for high-performance, large, integrated, high-strength, and low-cost metal structural parts in the aerospace and automotive industries [1,2], metal additive manufacturing printing technology has become a hot topic for research and applications in additive manufacturing technology [3,4]. According to morphology, the raw materials of metal additive manufacturing technology can be divided into powder and wire [5]. With its advantages of high material utilization rate, high deposition rate, low cost, and low pollution, wire has been widely used in the field of metal additive manufacturing [6-8]. Current mainstream metal wire additive manufacturing technologies include Laser Additive Manufacturing (LAM), Electron Beam Additive Manufacturing (EBAM), Wire and Arc Additive Manufacturing (WAAM), and Wire and Plasma Additive Manufacturing (WPAM) [9]. LAM has high forming accuracy, high flexibility, and a short manufacturing cycle [10], but has low energy utilization; the residual stress of the formed part is large, and the cost of the laser head is high [11]. EBAM has high energy utilization and forming efficiency, but the size of the formed parts is limited by the volume of the vacuum chamber and the consequent increase in cost [12-14]. WAAM and WPAM have the advantages of low cost and high deposition efficiency [15], but the process parameters of both are variable and complex, and the dimensional accuracy of the manufactured parts is not high $[16,17]$. Reducing manufacturing costs, improving forming accuracy and efficiency, and ensuring forming quality are of great significance to the widespread application of metal wire additive manufacturing technology. 
In recent years, scholars have proposed a new AM method [18,19]. The positive and negative terminals of a power supply are connected, respectively, with the metal wire and the metal substrate. After a current is introduced, the metal wire and the substrate contact and generate Joule heat, which melts the tip of the metal wire, forms a molten droplet, and deposits. With the movement of the workbench and wire feeding mechanism, the process can be repeated to form dense metal parts. Compared with the current mainstream metal fuse additive manufacturing technologies, Resistance Additive Manufacturing (RAM) greatly improves energy utilization through closed-loop energy transfer [20]. The smaller heat-affected zone ensures part forming accuracy [21]. The simple equipment structure reduces manufacturing costs [18]. Unlike WAAM, RAM uses a lower voltage to avoid arcing, and the contact energy transfer has a higher energy efficiency and smaller heataffected zone. The droplet size can be adjusted by controlling the current and wire feeding speed, resulting in adjustability and higher accuracy. RAM provides a new direction for low-energy, low-cost, and high-precision additive manufacturing.

To date, some scholars have conducted exploratory research on RAM based on the principle of resistance welding. Lu et al. [22] found that the surface tension of metal droplets decreased with the increase in temperature during high-speed welding. Chen [23], from the Institute of Welding, Beijing University of Technology, studied the influence of gravity on the metal melting in the transition stage during the metal wire melting and deposition forming process of resistance heating. The results showed that, in the ground environment, the metal melt transition stage was affected by surface tension and electromagnetic contraction force, allowing it to overcome gravity to transition to the substrate.

However, all of the above studies were theoretical, and researchers have not yet printed single or multiple layers that could be better overlapped. In this paper, a RAM heat source model was established based on the Joule heat principle, and the temperature field of the melting coating process under different process parameters was simulated. The single-channel melting coating process parameters were optimized, and the feasibility of the process was verified through the experimental verification of the built RAM equipment, providing experimental information and reference data for the development of RAM.

\section{Materials and Methods}

The forming principle of RAM technology is shown in Figure 1. The positive and negative electrodes of the programmable power supply are connected with the wire and the metal substrate, respectively. The wire is transported by the pulsating wire feeder; when the wire is in contact with the substrate, the current flows through the metal wire, and the tip metal wire in contact with the substrate is generated by thermal resistance melting through the Joule effect. As the workbench moves, the wire continues to be fed and melts the tip metal wire, repeating this process to form dense metal parts. The forming process is protected by inert gas (Ar) to avoid oxidation. A high-speed camera system CCD and a voltage-current acquisition system are used to achieve the monitoring of the image changes and electrical signal changes during the melting of the wire. This technology uses low voltage and high current to avoid arcing during the forming process. 


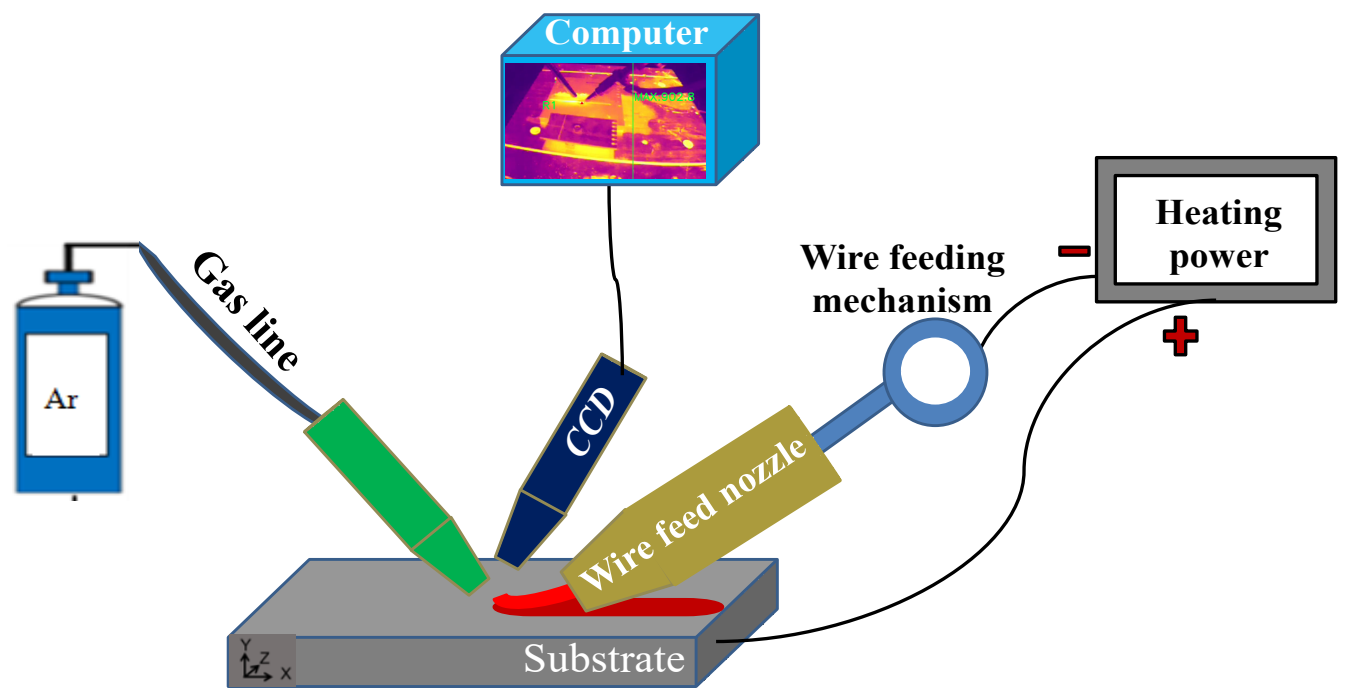

Figure 1. Forming schematic diagram of RAM.

In this paper, Ti-6Al-4V titanium alloy wire with a diameter of $0.8 \mathrm{~mm}$ was selected as the melting material. The substrate was a Ti-6Al-4V titanium alloy plate with a thickness of $5 \mathrm{~mm}$. The physical parameters of the Ti-6Al-4V titanium alloy are shown in Table 1 [24].

Table 1. Physical parameters of Ti-6Al-4V.

\begin{tabular}{ccccccc}
\hline Material & $\begin{array}{c}\text { Density } \\
\left(\mathbf{g} / \mathbf{c m}^{3}\right)\end{array}$ & $\begin{array}{c}\text { Electrical Resistivity } \\
(\mathbf{\Omega} \cdot \mathbf{m})\end{array}$ & $\begin{array}{c}\text { Melting Point } \\
\left({ }^{\circ} \mathbf{C}\right)\end{array}$ & $\begin{array}{c}\text { Thermal } \\
\text { Conductivity } \\
(\mathbf{W} / \mathbf{m} \cdot \mathbf{K})\end{array}$ & $\begin{array}{c}\text { Specific Heat } \\
\text { Capacity } \\
\left(\mathbf{k J} / \mathbf{k g} \cdot{ }^{\circ} \mathbf{C}\right)\end{array}$ & $\begin{array}{c}\text { Thermal Coefficient } \\
\text { of Expansion } \\
(\mathbf{1 0}\end{array}$ \\
\hline Ti6Al4V $/ \mathbf{K})$
\end{tabular}

Experimental equipment: The experimental workbench was modified from a $\mathrm{BCH} 850$ high-speed CNC milling machine using the programmable pulse power supply developed by ITECH company, with current range $0-300 \mathrm{~A}$, voltage $0-80 \mathrm{~V}$, maximum power $24,000 \mathrm{~W}$, as shown in Figure 2.

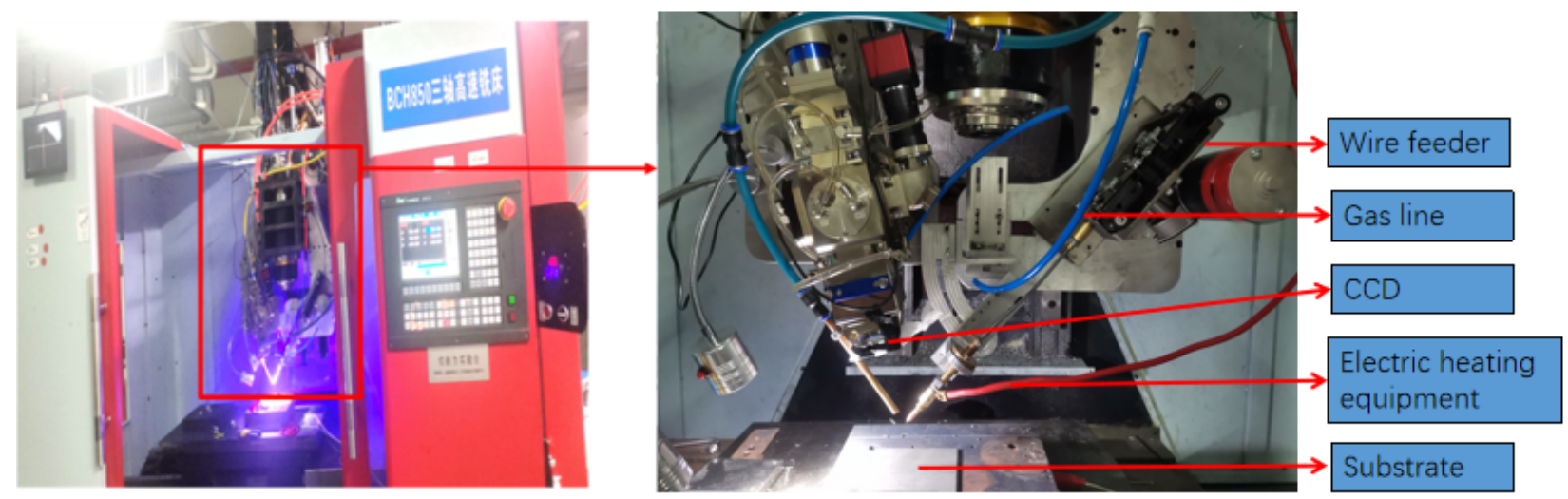

Figure 2. Experimental equipment. 


\section{Numerical Simulation}

\subsection{Deposition Principle and Establishment of Temperature Field Equation}

In the process of metal melting and deposition, the metal wire flows steadily into the molten pool. The material utilization rate of the deposition process can reach almost $100 \%$, and the unit of deposition rate is kilograms per second.

$$
\dot{m}=\rho v_{f} \cdot \frac{1}{4} \pi D^{2}=\rho v_{S} \cdot A
$$

where $D$ is the filler wire diameter, $A$ is the cross-sectional area formed by the cladding, $v_{f}$ and $v_{s}$ are respectively the wire feeding speed and the laser scanning speed [25]. Under the influence of gravity, due to the limitation of the substrate, the molten metal will extend in the horizontal direction when the paste-like filament enters the molten pool. The spatial concentration distribution of mass flow is similar to the Gaussian distribution defined by the following Equation:

$$
M_{\text {wire }}=\frac{\eta \dot{m}}{\pi R_{m}^{2}} \exp \left(\frac{-\eta r^{2}}{R_{m}^{2}}\right)
$$

where $r$ is the radial distance from the center, and $\eta$ and $R m$ represent the mass flow distribution factor and effective radius, respectively. The mass concentration distribution is related to the wire feed rate and viscosity. The mass increase process can be realized by adding the following external mass source term to the conservation of the mass Equation:

$$
\dot{S}_{\text {mass }}=M_{\text {wire }} \cdot \delta\left(x-x_{m}\right)
$$

where $\delta$ is the incremental function and $x_{m}$ is the position of the source at a fixed distance from the bottom of the molten pool.

In metal additive manufacturing, the laser forms a molten pool on the surface of the substrate, which is then thermally diffused throughout the substrate. The contact between the substrate and the wire will generate convective heat transfer, which in turn affects the temperature field $[26,27]$.

The temperature field establishment of a three-dimensional model needs to be based on the Fourier law of heat conduction and the law of conservation of energy, and then the governing equation of the heat transfer problem is established: the temperature $T$ function in three coordinates $x, y, z$ and time $t$ as parameters should satisfy the following Equation:

$$
\rho_{c} \frac{\partial T}{\partial t} \pm \bar{Q}=\frac{\partial}{\partial x}\left(k \frac{\partial T}{\partial x}\right)+\frac{\partial}{\partial y}\left(k \frac{\partial T}{\partial y}\right)+\frac{\partial}{\partial z}\left(k \frac{\partial T}{\partial z}\right)
$$

where $\rho, c$, and $k$ are the density, specific heat capacity, and thermal conductivity of the wire, respectively; $T(x, y, z, t)$ is the temperature distribution function; $Q$ is the latent heat of fusion released during the wire forming process, and the heat release process is taken as "-", absorb heat to get "+".

\subsection{Geometric Model and Meshing}

The single-channel melting layer model shown in Figure 3a was established by Ansys and meshed (shown in Figure 3b). The melting layer was $30 \mathrm{~mm}$ in length, $0.8 \mathrm{~mm}$ in diameter, and $0.6 \mathrm{~mm}$ in height. Using hexahedral cells to mesh improved the computational efficiency. The total number of elements was 1350 and the number of nodes was 7567 . 


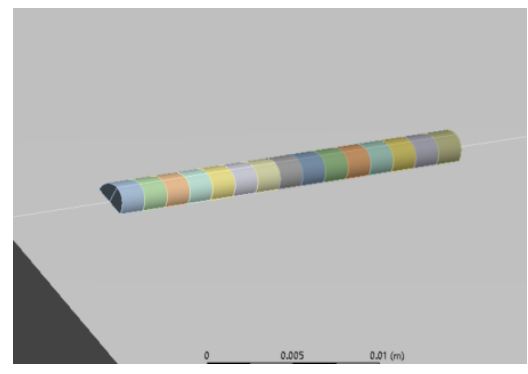

(a)

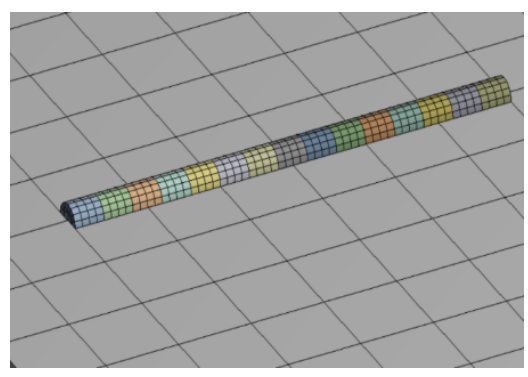

(b)

Figure 3. Geometric model and meshing. (a) Geometric model; (b) Geometric model with grids after meshing.

In the process of simulation analysis, in order to improve the efficiency of calculation and reduce the complexity of multifactor interaction in the actual melting process, the simulation process was reasonably simplified and the following assumptions were made:

(1) The heat transfer of materials in solid and molten states is continuous, and the parameters such as thermal conductivity and specific heat capacity involved in heat transfer are treated according to the continuous heat transfer.

(2) The loaded resistance heat source is the body heat source, which is loaded in the form of command flow generated by the expression of heat flux at the classical Ansys interface in the transient thermal analysis.

(3) It is assumed that the thermal absorption rate and thermal conductivity of the material do not change in the printing process.

(4) The effect of latent heat on temperature field is ignored.

\subsection{Material Assignment and Boundary Setting}

\subsubsection{Material Assignment}

The melting material and substrate were Ti-6Al-4V titanium alloy. The physical parameters are shown in Table 1 . The initial condition was ambient temperature $\left(22^{\circ} \mathrm{C}\right)$.

\subsubsection{Boundary Conditions}

The boundary condition was the heat transfer condition on the surface of the temperature field.

$$
Q=h f\left(T_{s}-T_{b}\right)
$$

where $h$ is convective heat transfer coefficient, $T_{s}$ is surface temperature, and $T_{b}$ is air temperature.

\subsubsection{Insertion of Life and Death Unit}

It was assumed that the length of a single melting coating layer was $\mathrm{L}=30 \mathrm{~mm}$, and it was divided into 15 segments. Each segment corresponded to a life and death unit, and each analysis step corresponded to a life and death unit, which was then divided into 15 steps in total. The scanning speed was set to $V=5 \mathrm{~mm} / \mathrm{s}$. The scanning time of the first layer was calculated as $6 \mathrm{~s}$ according to $\mathrm{T}=\mathrm{L} / \mathrm{V}$, and then the total time $\mathrm{t}=6 \mathrm{~s}$ was divided by the number of steps (15) of the analysis step according to StepTime $=\mathrm{T} /$ Substeps, and the resulting time substep was $0.4 \mathrm{~s}$.

\subsubsection{Selection of Heat Sources and Application of Loads}

The characteristic of resistance heating is that the heat flux of the heat source acts not only on the surface of the wire, but also on the depth direction of the part. At this time, it should be regarded as a volume distribution heat source. Here, the double ellipsoid heat source in the proposed volume heat source was suitable to describe the molten pool shape when the heat source moved in the depth direction. In order to reduce the time of the 
simulation process and simplify the calculation, this paper used a similar semi-ellipsoid distribution heat source.

As shown in Figure 4, the elliptic half axis was the maximum heat flux at the center of the heat source, i.e., the origin of the coordinate system $(0,0,0)$, and the function expression of the heat flux distribution was as follows:

$$
q(x, y, z)=q_{m} \cdot \exp \left(-A x^{2}-B y^{2}-C z^{2}\right)
$$

$A, B$, and $C$ are the heat flux volume distribution parameters through a series of derivations:

$$
q(x, y, z)=\frac{6 \sqrt{3} Q}{a_{h} b_{h} c_{h} \pi^{1.5}} \cdot \exp \left(\frac{-3 x^{2}}{a_{h}^{2}}+\frac{-3 y^{2}}{b_{h}^{2}}+\frac{-3 z^{2}}{c_{h}^{2}}\right)
$$

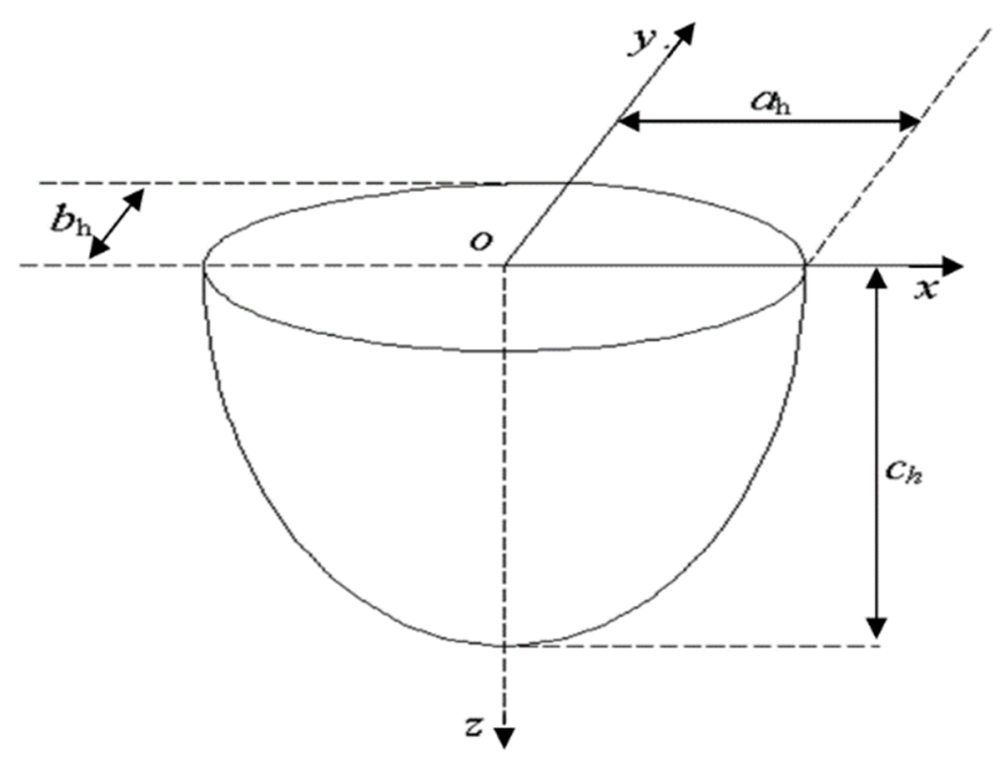

Figure 4. Schematic diagram of semi-ellipsoid domain.

\subsection{Parameter Setting}

In this paper, care was taken to ensure the consistency and comparability of the calculations. It was found through previous experiments that sparks will occur in the printing process when the voltage is too large (Figure $5 a$ ), that the wire cannot be effectively melted when the voltage is too small, and that good results without sparks can be achieved when the voltage is $10 \mathrm{~V}$ (Figure 5b). When the workbench moves too slowly, the conductive nozzle becomes blocked (Figure 5c); if it moves too fast, the wire cannot be melted (Figure 5d), but it is stable at $5 \mathrm{~mm} / \mathrm{s}$. When the gas flow rate is too low, the oxidation is more significant (Figure $5 \mathrm{e}$ ). When the gas flow rate reaches $0.7 \mathrm{~m}^{3} / \mathrm{h}$, oxidation can be effectively prevented (Figure $5 \mathrm{f}$ ). In this paper, the current was used as a single variable to analyze whether the wire would melt better under different currents. The current values were $130 \mathrm{~A}, 160 \mathrm{~A}$, and $190 \mathrm{~A}$, respectively. The wire feeding speed was initially set as $2.4 \mathrm{~m} / \mathrm{min}$. The parameter selection is shown in Table 2. 


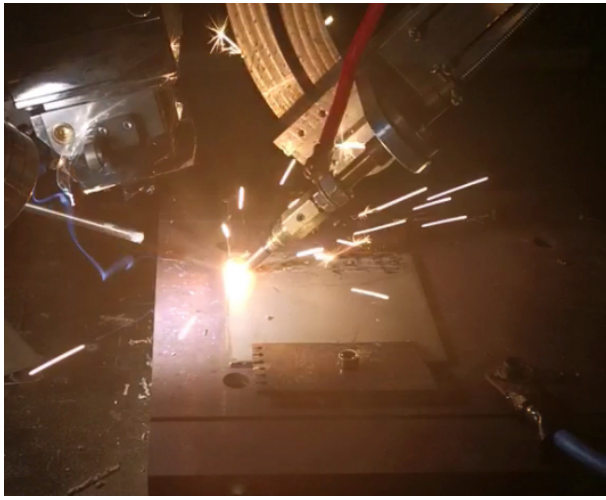

(a)

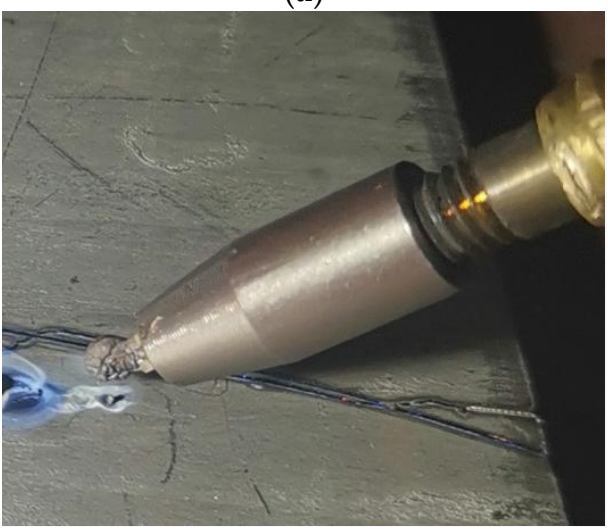

(c)

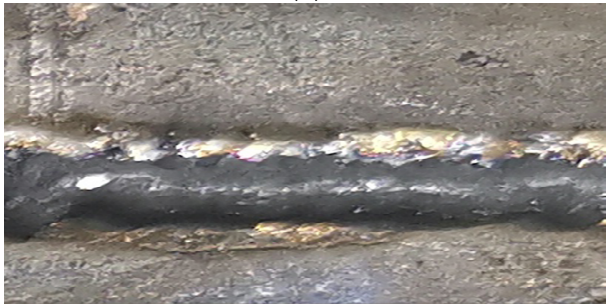

(e)

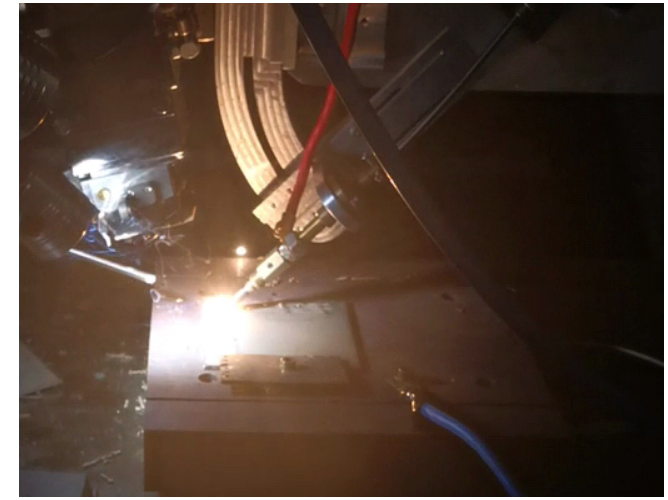

(b)

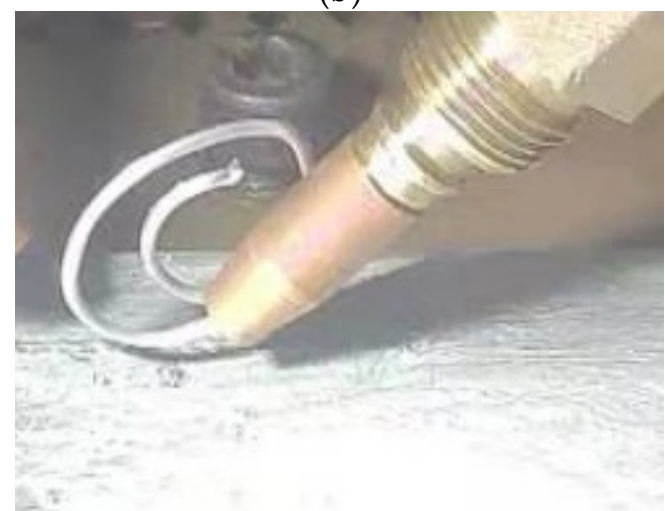

(d)

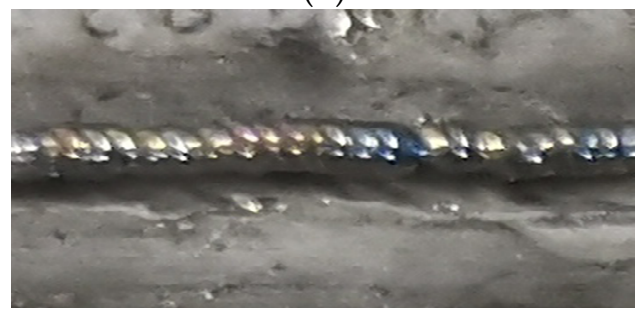

(f)

Figure 5. Comparison of parameters and effects. (a) The voltage is too large. (b) The voltage is $10 \mathrm{~V}$. (c) The workbench moves too slowly. (d) The workbench moves too fast. (e) The gas flow rate is too low. (f) The gas flow rate is $0.7 \mathrm{~m}^{3} / \mathrm{h}$.

Table 2. Process parameters.

\begin{tabular}{cccccc}
\hline Number & $\begin{array}{c}\text { Electric } \\
\text { Current (A) }\end{array}$ & $\begin{array}{c}\text { Gas Flow } \\
\left(\mathbf{m}^{3} / \mathbf{h}\right)\end{array}$ & $\begin{array}{c}\text { Wire Feeding Speed } \\
(\mathbf{m} / \mathbf{m i n})\end{array}$ & $\begin{array}{c}\text { Voltage } \\
(\mathbf{V})\end{array}$ & $\begin{array}{c}\text { Workbench Moving } \\
\text { Speed }(\mathbf{m m} / \mathbf{s})\end{array}$ \\
\hline 1 & 130 & 0.7 & 2.4 & 10 & 5 \\
2 & 160 & 0.7 & 2.4 & 10 & 5 \\
3 & 190 & 0.7 & 2.4 & 10 & 5 \\
\hline
\end{tabular}

Monitoring the real-time temperature change of the melting coating process is very beneficial to the study of the melting coating forming process and the optimization of the later process parameters. In this paper, the temperature probe monitoring points A, B, C, and $\mathrm{D}$ were selected to obtain the temperature-time change images of different process parameters, as shown in Figure 6. 


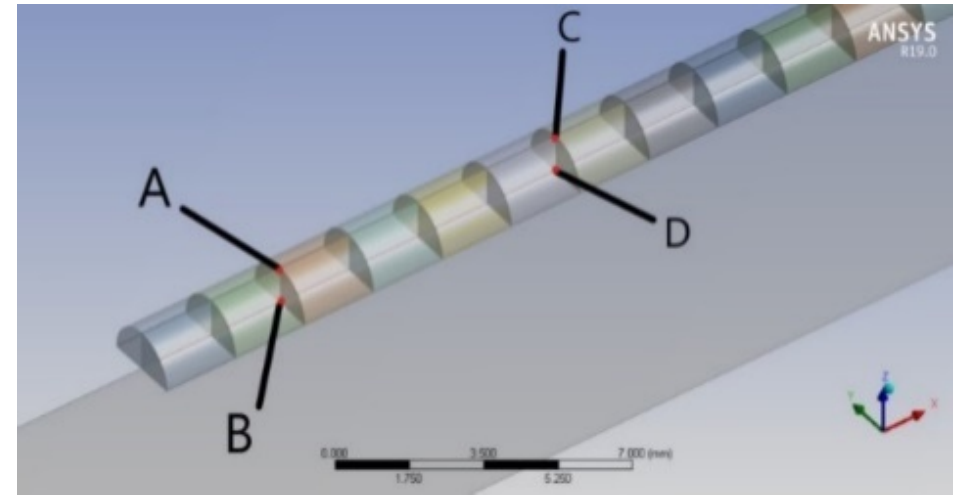

Figure 6. Monitoring points for 4 temperature probes.

\section{Results}

\subsection{Results of Simulation}

The temperature-time curves under three groups of currents obtained by simulation are shown in Figure 7, where A, B, C, and D are the temperatures measured at the four positions shown in Figure 6.

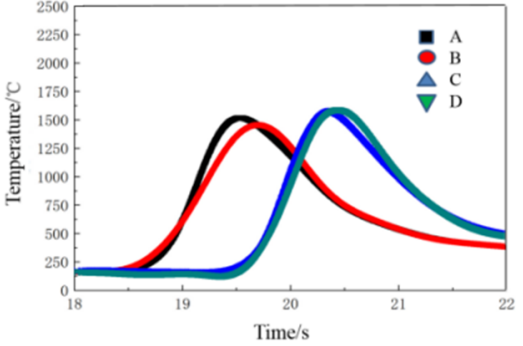

(a)

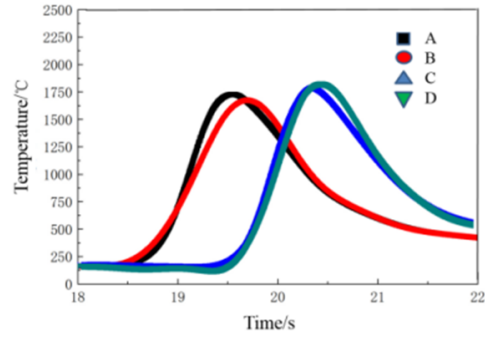

(b)

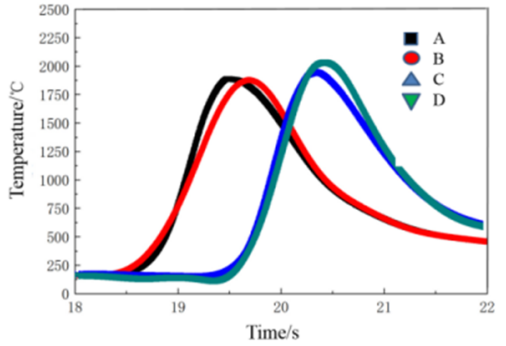

(c)

Figure 7. Temperature-time curves. (a) 130 A; (b) 160 A; (c) 190 A.

As shown in Figure 7a, when the current was $130 \mathrm{~A}$, the temperatures of the four points were lower than or close to the melting point of the material, which meant that the coating layer could not adhere to the substrate. It can be seen from Figure $7 \mathrm{~b}$ that when the current was $160 \mathrm{~A}$, the temperature of the four points exceeded the melting point; it can be seen from Figure 7c that when the current increased to $190 \mathrm{~A}$, the temperatures of the four points exceeded the melting point more. It can be seen from Figure $7 \mathrm{~b}, \mathrm{c}$ that under these two current values, the wire could be melted, and the coating layer could be well combined with the substrate, but excessively high temperatures may cause melting to occur too fast and affect the forming appearance.

\subsection{Influence of Current on Forming Appearance}

When other parameters remained unchanged, the influence of current on the forming appearance was experimentally studied, as shown in Table 3. When the current was $130 \mathrm{~A}$, the generated resistance heat was insufficient to melt the wire, resulting in the coiling of the wire and its failure to adhere to the substrate, resulting in poor appearance. When the current was $160 \mathrm{~A}$, the droplet size was small and uniform, the fusion layer was firmly adhered to the substrate, and the sample is good. When the current was $190 \mathrm{~A}$, the resistance heat was too large, resulting in excessive melting speed and uneven droplet size, which could not form continuous deposition on the substrate. Thus, the current had a great influence on the shape of the RAM. 
Table 3. Influence of current on forming appearance.

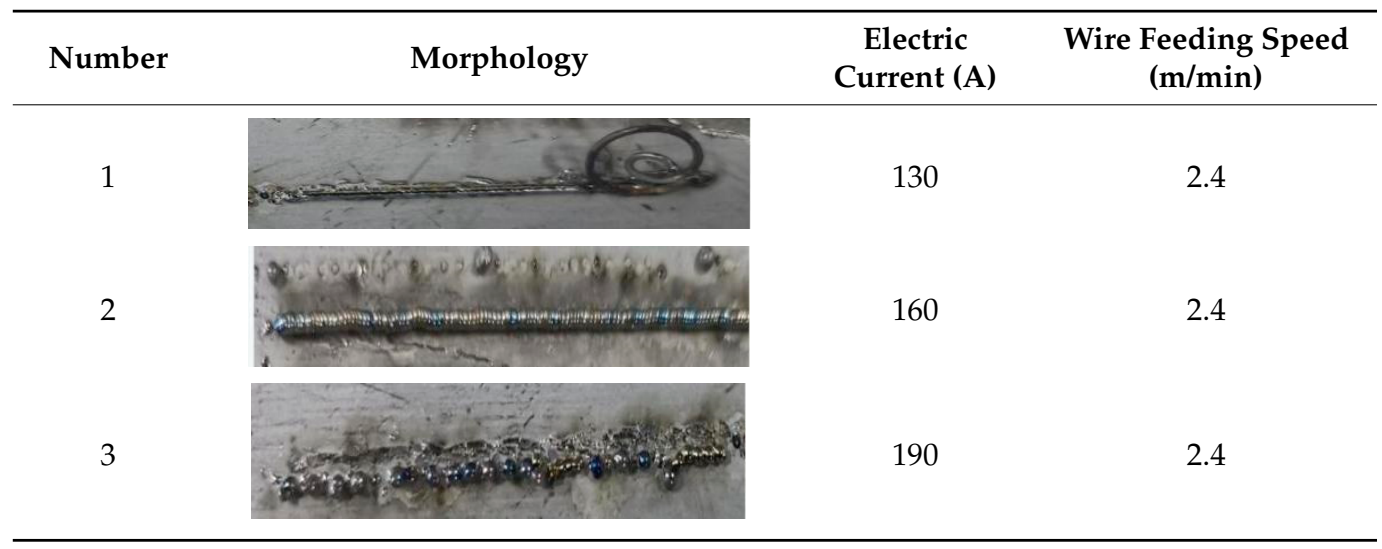

\subsection{Influence of Wire Feeding Speed on Forming Appearance}

When other parameters remained unchanged, the influence of wire feeding speed on the forming appearance was studied experimentally, as shown in Table 4 . When the wire feeding speed was $2.0 \mathrm{~m} / \mathrm{min}$, the wire feeding speed was too slow to form continuously, and the appearance was not good. Under the same current, when the wire feeding speed was $2.4 \mathrm{~m} / \mathrm{min}$, dense continuous forming was realized, which was firmly adhered to the substrate and had good shape. When the wire feeding speed was $2.8 \mathrm{~m} / \mathrm{min}$, the melting speed of the wire could not keep up with the wire feeding speed and the wire could not be completely melted, and the shape of the formed sample was distorted. It can be seen that the wire feeding speed had a great influence on the shape of the formed RAM.

Table 4. Influence of wire feeding speed on forming appearance.

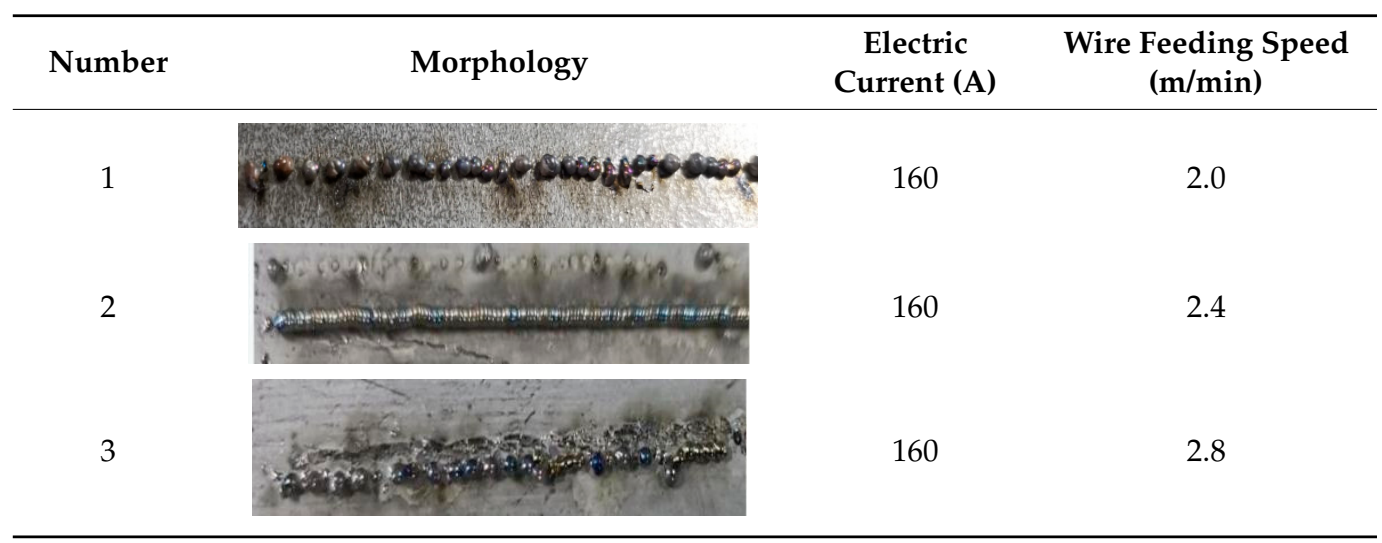

From the above experimental results, it can be concluded that when the current is $160 \mathrm{~A}$, the wire feeding speed is $2.4 \mathrm{~m} / \mathrm{min}$, the voltage is $10 \mathrm{~V}$, the gas flow is $0.7 \mathrm{~m}^{3} / \mathrm{h}$, and the workbench moving speed is $5 \mathrm{~mm} / \mathrm{s}$, the appearance is the best. The frequency of the current measured by oscilloscope under this process parameter was $36 \mathrm{~Hz}$ (as shown in Figure 8). One frequency forms a molten droplet; the higher the frequency is, the smaller the droplet that can be formed, and the higher the forming accuracy. 


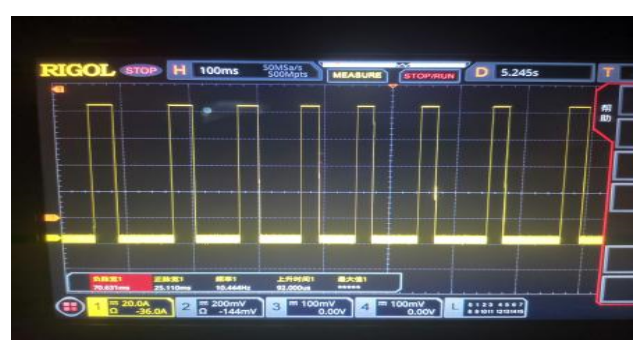

(a)

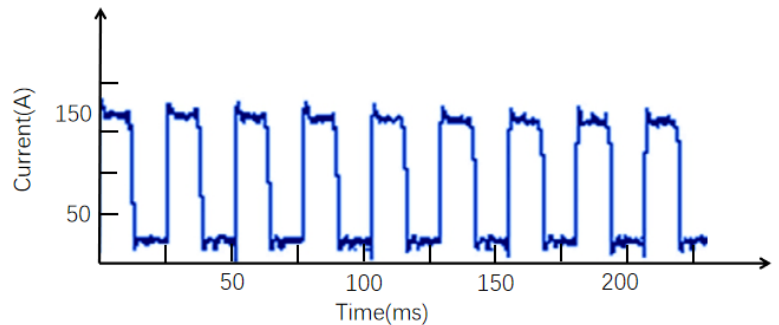

(b)

Figure 8. Current frequency. (a) Measurement. (b) Analysis.

\subsection{Forming and Density Test of Single-Pass Multilayer}

Using the optimized single-layer process parameters for single-pass multilayer fusion, the forming appearance shown in Figure 9 can be obtained.

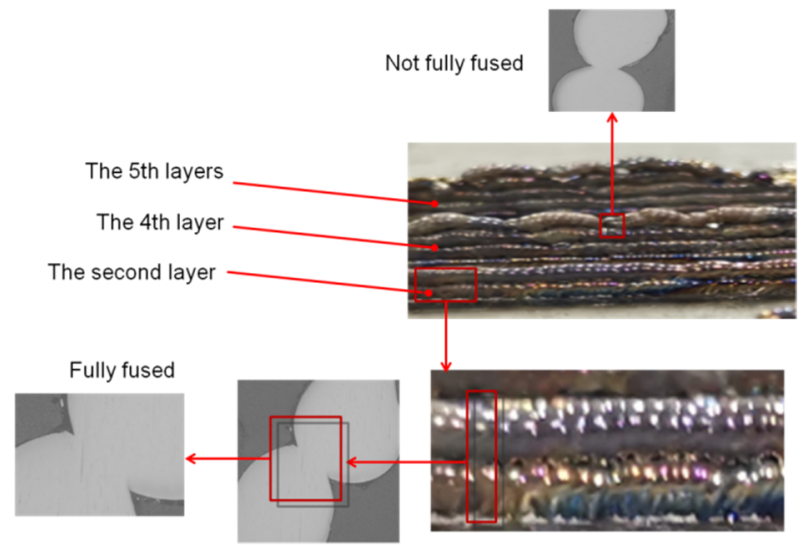

Figure 9. Single pass multi-layer forming.

Relative density is an important index of the internal quality of a metal part. In this paper, the density of a part was measured using Archimedes' principle. After degreasing and cleaning, the samples were weighed using a balance in air and then, according to Equation (5), submerged in water to obtain the density of the samples.

$$
\rho=\frac{\mathrm{m}_{1}}{\mathrm{~m}_{1}-\mathrm{m}_{2}} \rho_{1}
$$

where $m_{1}$ is the mass of the sample to be tested measured in air, $m_{2}$ is the mass of the sample to be tested fully immersed in water, $\rho$ is the density of the tested sample, and $\rho_{1}$ is the density of water.

The balance used in the experiment was an AG204 electronic balance produced by Mettler Toledo, Zürich, Switzerland, with a measurement accuracy of $0.1 \mathrm{mg}$ and a maximum range of $210 \mathrm{~g}$. The relative density of the sample produced via the RAM method was determined to be $97.7 \%$ (results shown in Table 5). It can be seen that the denseness of the part was high and that under better process parameters, the layers melted sufficiently to achieve a metallurgical bond between the overlapping layers of material.

Table 5. Results of relative density.

\begin{tabular}{cccccc}
\hline Material & $\begin{array}{l}\mathbf{m}_{\mathbf{1}} \\
(\mathbf{g})\end{array}$ & $\begin{array}{l}\mathbf{m}_{\mathbf{2}} \\
(\mathbf{g})\end{array}$ & $\begin{array}{c}\boldsymbol{\rho} \\
\left(\mathrm{g} / \mathbf{c m}^{3}\right)\end{array}$ & $\begin{array}{c}\boldsymbol{\rho}_{\mathbf{0}} \\
\left(\mathrm{g} / \mathrm{cm}^{3}\right)\end{array}$ & $\begin{array}{c}\text { Relative Density } \\
(\mathbf{\%})\end{array}$ \\
\hline Ti-6Al-4V & 9.0851 & 6.9577 & 4.2705 & 4.371 & 97.7 \\
\hline where $\varrho_{0}$ is the theoretical density of Ti-6Al-4V.
\end{tabular}




\section{Conclusions}

In this paper, a RAM simulation model was established to study the temperature change of the melted layer under different currents, and the current parameter range of the melted wire was preliminarily obtained. An experimental system was built, and the correctness of the simulation results was verified. The influence of current and wire feeding speed on the forming appearance was studied, and single channel and multilayer continuous printing were carried out, verifying the feasibility of the process. The main conclusions are as follows:

(1) In the RAM process, the main influencing factors are current, wire feeding speed, voltage, workbench moving speed, and gas flow. Current and wire feeding speed mainly affect the appearance of the molten coating layer. Voltage affects whether spark splash occurs in the printing process. Platform moving speed affects whether the printing process is at the correct temperature. Gas flow affects the oxidation degree.

(2) When the material is Ti- $6 \mathrm{Al}-4 \mathrm{~V}$, the current is $160 \mathrm{~A}$, the voltage is $10 \mathrm{~V}$, the wire feeding speed is $2.4 \mathrm{~m} / \mathrm{min}$, the moving speed of the workbench is $5 \mathrm{~mm} / \mathrm{s}$, and the gas flow rate is $0.7 \mathrm{~m}^{3} / \mathrm{h}$, the forming morphology of the single-channel coating layer is the best.

(3) By optimizing the process, a single-channel five-layer sample was printed, and its relative density was $97.7 \%$. Good overlap between layers was achieved, which verified the feasibility of RAM at the experimental level and provided reference data for the subsequent development of this technology.

Author Contributions: Conceptualization, S.L. and B.L.; methodology, K.M.; software, C.X.; validation, S.L. and K.M.; formal analysis, L.Y.; investigation, S.L. and K.M.; resources, S.L. and B.L.; data curation, K.M. and C.X.; writing-original draft preparation, S.L. and K.M.; writing-review and editing, S.L. and K.M.; visualization, S.L.; supervision, K.M.; project administration, L.Y.; funding acquisition, C.X. All authors have read and agreed to the published version of the manuscript.

Funding: This research was funded by State Key Laboratory for Manufacturing Systems Engineering, China. Funding number: sklms2021016.

Institutional Review Board Statement: Not applicable.

Informed Consent Statement: Not applicable.

Data Availability Statement: Not applicable.

Acknowledgments: Suli Li would like to thank Xueping Yan, Haimin Zhou, Jie Xiong, Zhuang Gao, Cong Wang and Jingsheng Zhao for providing materials used for experiments and academic guidance.

Conflicts of Interest: The authors declare no conflict of interest.

\section{References}

1. Lu, B. Additive manufacturing-Current situation and future. China Mech. Eng. 2020, 31, 19.

2. Calignano, F. Additive Manufacturing (AM) of Metallic Alloys. Crystals 2020, 10, 704. [CrossRef]

3. Frazier, W.E. Metal additive manufacturing: A review. J. Mater. Eng. Perform. 2014, 23, 1917-1928. [CrossRef]

4. Sun, C.; Wang, Y.; McMurtrey, M.D.; Jerred, N.D.; Liou, F.; Li, J. Additive manufacturing for energy: A review. Appl. Energy 2021, 282, 116041. [CrossRef]

5. Jackson, M.A.; Van Asten, A.; Morrow, J.D.; Min, S.; Pfefferkorn, F.E. A comparison of energy consumption in wire-based and powder-based additive-subtractive manufacturing. Procedia Manuf. 2016, 5, 989-1005. [CrossRef]

6. Węglowski, M.S.; Błacha, S.; Jachym, R.; Dworak, J.; Rykała, J. Additive manufacturing with wire-Comparison of processes. AIP Conf. Proc. 2019, 2113, 150016.

7. Vimal, K.E.K.; Srinivas, M.N.; Rajak, S. Wire arc additive manufacturing of aluminium alloys: A review. Mater. Today Proc. 2021, 41, 1139-1145. [CrossRef]

8. Hwang, M.J.; Cho, J. Laser Additive Manufacturing Technology Review. J. Weld. Join. 2014, 32, $354-357$.

9. Yilmaz, O.; Ugla, A.A. Shaped metal deposition technique in additive manufacturing: A review. Proc. Inst. Mech. Eng. Part B J. Eng. Manuf. 2016, 230, 1781-1798. [CrossRef] 
10. Galati, M.; Calignano, F.; Viccica, M.; Iuliano, L. Additive manufacturing redesigning of metallic parts for high precision machines. Crystals 2020, 10, 161. [CrossRef]

11. Ding, Y.; Akbari, M.; Kovacevic, R. Process planning for laser wire-feed metal additive manufacturing system. Int. J. Adv. Manuf. Technol. 2018, 95, 355-365. [CrossRef]

12. Fuchs, J.; Schneider, C.; Enzinger, N. Wire-based additive manufacturing using an electron beam as heat source. Weld. World 2018, 62, 267-275. [CrossRef]

13. Miyata, Y.; Okugawa, M.; Koizumi, Y.; Nakano, T. Inverse columnar-equiaxed transition (CET) in 304 and 316 L stainless steels melt by electron beam for additive manufacturing (AM). Crystals 2021, 11, 856. [CrossRef]

14. Weglowski, M.S.; Błacha, S.; Pilarczyk, J.; Dutkiewicz, J.; Rogal, Ł. Electron beam additive manufacturing with wire-analysis of the process. AIP Conf. Proc. 2018, 1960, 140015.

15. Rodrigues, T.A.; Duarte, V.; Miranda, R.M.; Santos, T.G.; Oliveira, J.P. Current status and perspectives on wire and arc additive manufacturing (WAAM). Materials 2019, 12, 1121. [CrossRef]

16. Derekar, K.S. A review of wire arc additive manufacturing and advances in wire arc additive manufacturing of aluminium. Mater. Sci. Technol. 2018, 34, 895-916. [CrossRef]

17. Artaza, T.; Suárez, A.; Veiga, F.; Braceras, I.; Tabernero, I.; Larrañaga, O.; Lamikiz, A. Wire arc additive manufacturing Ti6Al4V aeronautical parts using plasma arc welding: Analysis of heat-treatment processes in different atmospheres. J. Mater. Res. Technol. 2020, 9, 15454-15466. [CrossRef]

18. Klobcara, D.; Balosb, S.; Busicc, M.; Duricd, A.; Lindica, M.; Scetineca, A. WAAM and Other Unconventional Metal Additive. Manuf. Technol. 2020, 45, 1-9.

19. Lee, C.Y.; Taylor, A.C.; Nattestad, A.; Beirne, S.; Wallace, G.G. 3D printing for electrocatalytic applications. Joule 2019, 3, 1835-1849. [CrossRef]

20. Vafadar, A.; Guzzomi, F.; Rassau, A.; Hayward, K. Advances in metal additive manufacturing: A review of common processes, industrial applications, and current challenges. Appl. Sci. 2021, 11, 1213. [CrossRef]

21. Khan, M.S.; Sanchez, F.; Zhou, H. 3-D printing of concrete: Beyond horizons. Cem. Concr. Res. 2020, 133, 106070. [CrossRef]

22. Lu, Z.; Huang, P.; Chen, S.; Li, Y. Mechanism of undercut in high speed welding based on moveless TIG welding. Trans. Jwri 2010, 39, 197-198.

23. Chen, S.; Yuan, C.; Jiang, F.; Yan, Z.; Zhang, P. Study on Heat Generation Mechanism and Melting Behavior of Droplet Transition in Resistive Heating Metal Wires. Acta. Metall. Sin. 2018, 54, 1297-1310.

24. Dai, S.; Dai, X. Interpretation of the latest edition of GB/T 3620.1-2016 Titanium and Titanium Alloy grades and chemical Composition. Sci. Technol. Vis. 2019, 107-108. [CrossRef]

25. Wei, S.; Wang, G.; Nie, Z.; Huang, Z.; Rong, Y. Microstructure evolution of martensitic stainless steel in laser hot wire cladding with multiple heating passes. In TMS 2016 145th Annual Meeting E Exhibition; Springer International Publishing: Berlin/Heidelberg, Germany, 2016; pp. 191-198.

26. Shrestha, S.; Rauniyar, S.; Chou, K. Thermo-fluid modeling of selective laser melting: Single-track formation incorporating metallic powder. J. Mater. Eng. Perform. 2019, 28, 611-619. [CrossRef]

27. Peyre, P.; Dal, M.; Pouzet, S.; Castelnau, O. Simplified numerical model for the laser metal deposition additive manufacturing process. J. Laser Appl. 2017, 29, 022304. [CrossRef] 